Article

\title{
Synthesis and Characterization of Nano Boron Nitride Reinforced Magnesium Composites Produced by the Microwave Sintering Method
}

\section{Sankaranarayanan Seetharaman ${ }^{1}$, Jayalakshmi Subramanian ${ }^{1}$, Khin Sandar Tun ${ }^{2}$,} Abdelmagid S. Hamouda ${ }^{3}$ and Manoj Gupta ${ }^{1, *}$

1 Department of Mechanical Engineering, National University of Singapore, 9 Engineering Drive 1, Singapore 117576; E-Mails: seetharaman.s@nus.edu.sg (S.S.); mpejs@nus.edu.sg (J.S.)

2 Technology Development Centre, ITE College Central, H1-01, 2 Ang Mo Kio Drive, Singapore 567720; E-Mail: sandar_k_tun@ite.edu.sg

3 Mechanical and Industrial Engineering Department, Qatar University, Doha P.O. Box No. 2713, Qatar; E-Mail: hamouda@qu.edu.qa

* Author to whom correspondence should be addressed; E-Mail: mpegm@nus.edu.sg; Tel.: +65-6516-6358; Fax: +65-6779-1459.

Received: 11 April 2013; in revised form: 3 May 2013 / Accepted: 6 May 2013 /

Published: 10 May 2013

\begin{abstract}
In this study, magnesium composites with nano-size boron nitride (BN) particulates of varying contents were synthesized using the powder metallurgy (PM) technique incorporating microwave-assisted two-directional sintering followed by hot extrusion. The effect of nano-BN addition on the microstructural and the mechanical behavior of the developed $\mathrm{Mg} / \mathrm{BN}$ composites were studied in comparison with pure $\mathrm{Mg}$ using the structure-property correlation. Microstructural characterization revealed uniform distribution of nano-BN particulates and marginal grain refinement. The coefficient of thermal expansion (CTE) value of the magnesium matrix was improved with the addition of nano-sized BN particulates. The results of XRD studies indicate basal texture weakening with an increase in nano-BN addition. The composites showed improved mechanical properties measured under micro-indentation, tension and compression loading. While the tensile yield strength improvement was marginal, a significant increase in compressive yield strength was observed. This resulted in the reduction of tension-compression yield asymmetry and can be attributed to the weakening of the strong basal texture.
\end{abstract}


Keywords: metal matrix composites; microwave sintering; mechanical properties; microstructure; X-ray diffraction; scanning electron microscopy

\section{Introduction}

In recent years, the research and development of new magnesium materials is receiving increased attention, as they exhibits tremendous application potential in the aerospace and transportation sectors, owing to their weight saving capabilities. Besides being light, $\mathrm{Mg}$ also possesses excellent damping characteristics, machinability and good castability. However, its poor ductility at room temperature due to the low symmetry and the paucity of slip systems in the hexagonal closed packed (HCP) structure restrict its extensive application [1-4].

In $\mathrm{Mg}$, the thermomechanical processes, such as extrusion, results in a strong texture development aligning the basal planes strongly into the extrusion direction, which are highly unfavorable for basal slip to occur. Hence, the extruded Mg-materials exhibit poor ductility and different yield strengths under tension and compression. The compression yield stress is normally about $1 / 2$ or $3 / 4$ of the tension yield stress along the extrusion direction. Also, the tensile ductility of extruded Mg-based materials is limited, due to the difficulty in basal slip activation if the testing is carried out parallel to the extrusion direction [4-7]. Literature study reveals numerous attempts being made to improve the deformation behavior of $\mathrm{Mg}$ at room temperature [8-12]. In these studies, the property improvements are achieved primarily by the activation of non-basal slip systems/twinning, brought forth by texture modification through the addition of nanoscale reinforcements [8-12]. In this regard, boron nitride (BN) is an interesting material owing to its unique combination of properties, such as low density, high melting point, high thermal conductivity and high electrical resistivity [13,14]. Literature studies reveal the positive influence of boron nitride particles on the mechanical properties improvement in aluminum matrix composites [13,14]. However, in magnesium matrix composites, while the oxide reinforcements, such as $\mathrm{Al}_{2} \mathrm{O}_{3}, \mathrm{Y}_{2} \mathrm{O}_{3}$ and $\mathrm{ZrO}_{2}$, and the carbide reinforcements, like $\mathrm{SiC}$ in nanoscale, are extensively used by various researchers, no attempt has been made so far to synthesize nano-BN reinforced magnesium composites.

Alongside the development of new materials, unconventional processing techniques utilizing electromagnetic sources also result in energy savings, and in this regard, the microwave heating of metals has been proven as an efficient material processing technique [15]. Unlike directional microwave sintering, where the direction of heating is from inside to outside of the powder compact, the two directional rapid microwave sintering uses the combined action of microwaves and microwave-coupled external heating and has the major advantage of sintering the powder compacts at a relatively shorter period of time [15].

In the current work, nano-sized boron nitride particulates were incorporated in pure $\mathrm{Mg}$ through the powder metallurgy technique, using microwave sintering of the powder compacts. The effect of varying volume fractions of nano-BN addition on the microstructural and mechanical properties of pure $\mathrm{Mg}$ is investigated. The structure-property relationship is used to understand the observed mechanical behavior of the developed $\mathrm{Mg} / \mathrm{BN}$ nanocomposites. 


\section{Results and Discussion}

\subsection{Synthesis}

Pure $\mathrm{Mg}$ and its composites containing nano-BN particulates were successfully synthesized using powder metallurgy technique coupled with the microwave-assisted rapid sintering technique. The visual observation of the sintered billets and extruded rods did not reveal any defects and the successful synthesis of $\mathrm{Mg}$ materials without any macrostructural defects confirms the suitability of the process and process variables used in the study. The results of the characterization studies performed on the materials clearly indicate the feasibility of using microwave sintering to develop $\mathrm{Mg}$ composites $[8,11,12,16]$.

\subsection{Density and Porosity}

The results of density and porosity measurements conducted on the developed $\mathrm{Mg} / \mathrm{BN}$ nanocomposites are shown in Table 1. An increase in the experimental density values was observed due to the addition of BN-nanoparticulates, which is due to the relatively higher density of $\mathrm{BN}(2.98 \mathrm{~g} / \mathrm{cc})$ and, hence, increases with increasing BN addition. With regard to porosity, the obtained experimental values are relatively low in comparison to similar works, and this confirms the successful synthesis of near-dense materials with minimal porosity $(\leq 0.38 \%)$ through the powder metallurgy method assisted with microwave sintering followed by hot extrusion $[8,11,12,16]$.

Table 1. Results of density and porosity measurements.

\begin{tabular}{cccccc}
\hline S. No. & Material & BN (vol.\%) & Theoretical density & Experimental density & Porosity \\
\hline 1 & Pure Mg & 0.00 & 1.7400 & $1.7365 \pm 0.0011$ & $0.20 \pm 0.005$ \\
2 & Mg-0.5BN & 0.29 & 1.7436 & $1.7391 \pm 0.0034$ & $0.26 \pm 0.001$ \\
3 & Mg-1.5BN & 0.86 & 1.7506 & $1.7458 \pm 0.0014$ & $0.21 \pm 0.001$ \\
4 & Mg- $2.5 \mathrm{BN}$ & 1.44 & 1.7579 & $1.7512 \pm 0.0019$ & $0.38 \pm 0.004$ \\
\hline
\end{tabular}

\subsection{Microstructure}

The grain characteristics and morphology of developed $\mathrm{Mg}$ materials are shown in Figure 1 and listed in Table 2. The microstructural characteristics (average grain size and aspect ratio) of pure $\mathrm{Mg}$ and $\mathrm{Mg} / \mathrm{BN}$ composites based on grain size measurements conducted on the optical micrographs (Figure 1) are presented in Table 2. It revealed the unimodal distribution of grain size, which indicates one maxima for the grain size distribution, i.e., maximum grains of the same size. This shows the complete recrystallization of Mg-matrix during extrusion [17]. Further, the addition of nanosized BN particulates resulted in marginal reduction of average matrix grain size from $28 \mu$ to $19 \mu$ (Table 2). However, considering the standard deviation, it was observed to be minimal and independent of the reinforcement volume fraction. 
Figure 1. Optical micrographs showing the grain characteristics of: (a) pure $\mathrm{Mg}$; (b) $\mathrm{Mg}-0.5 \mathrm{BN}$; (c) $\mathrm{Mg}-1.5 \mathrm{BN}$; and (d) $\mathrm{Mg}-2.5 \mathrm{BN}$.
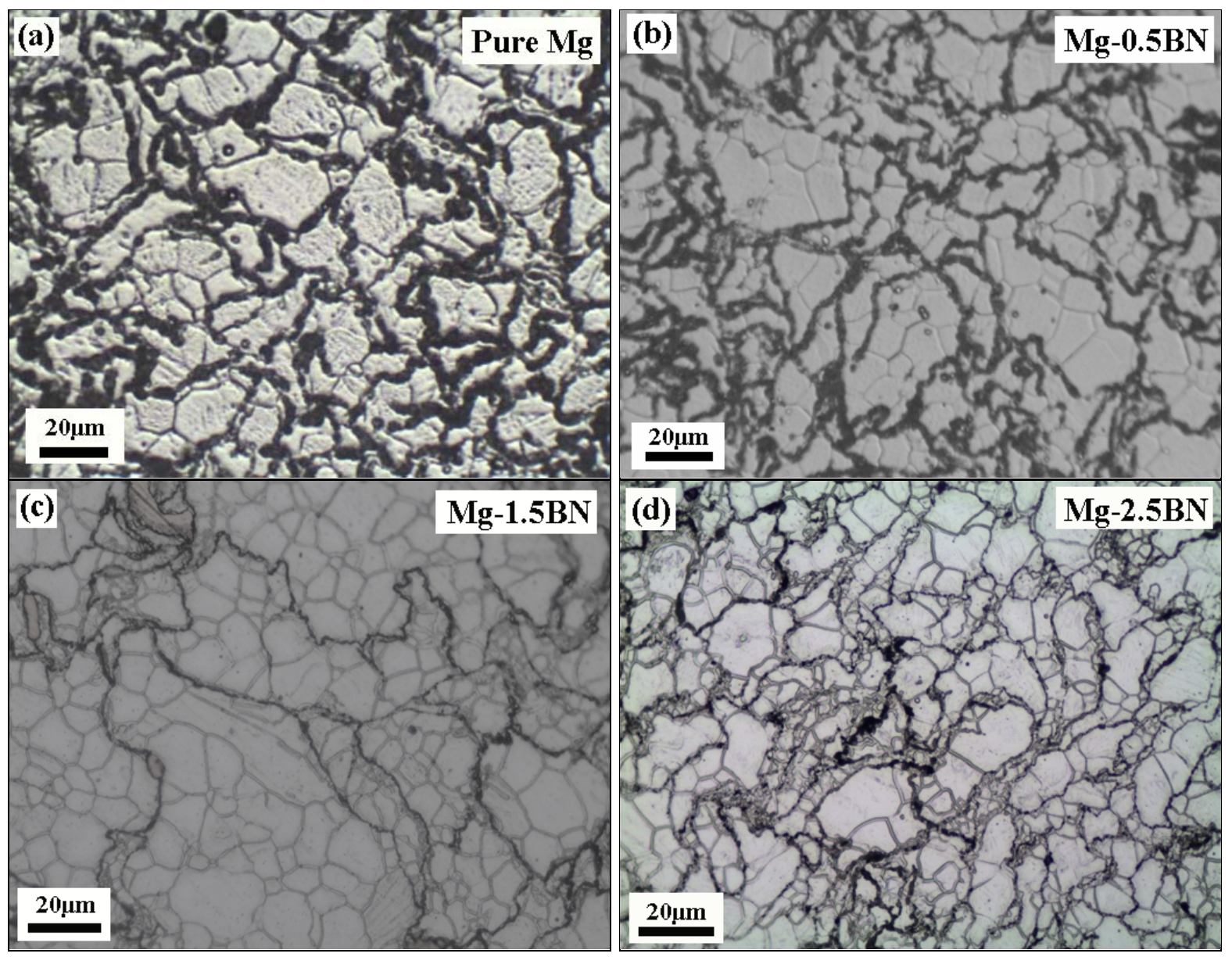

Table 2. Results of grain size measurements.

\begin{tabular}{cccc}
\hline S. No. & Material & Grain size $(\boldsymbol{\mu m})$ & Aspect ratio \\
\hline 1 & Pure Mg & $28.94 \pm 5.86$ & $1.61 \pm 0.55$ \\
2 & Mg-0.5BN & $21.42 \pm 2.67$ & $1.54 \pm 0.44$ \\
3 & Mg-1.5BN & $22.15 \pm 1.92$ & $1.67 \pm 0.39$ \\
4 & Mg- $2.5 \mathrm{BN}$ & $19.43 \pm 3.43$ & $1.56 \pm 0.42$ \\
\hline
\end{tabular}

The results of microstructural characterization studies conducted on the different $\mathrm{Mg} / \mathrm{BN}$ composite formulations indicate a fairly uniform distribution of nano-BN particulates inside the $\mathrm{Mg}$ matrix, as well as near to the grain boundaries, as seen in Figure 2a. The observed uniform distribution of nano-BN particulates in the Mg matrix, as seen Figure 2, could be attributed to the following reasons: (i) closer density values between the $\mathrm{Mg}$ matrix (1.7 g/cc) and $\mathrm{BN}$ reinforcements $(2.98 \mathrm{~g} / \mathrm{cc})$, resulting in lesser gravity assisted segregation problems during the blending, compaction and sintering process; (ii) suitable blending parameters used; and (iii) the efficient extrusion process capable of breaking down the agglomerates (if present) [8,17,18]. Literature study reveals that such homogeneous distribution of reinforcements can be achieved in the case of extruded materials with large deformation strain (Extrusion ratio-22.5:1), regardless of the size difference between the matrix and reinforcements $[17,18]$. 
Figure 2. Representative SEM micrographs showing (a) the distribution of nano-boron nitride $(\mathrm{BN})$ particulates; and (b) the interface between $\mathrm{Mg}$-matrix and the nano-BN particulates in $\mathrm{Mg}-1.5 \mathrm{BN}$ composite.

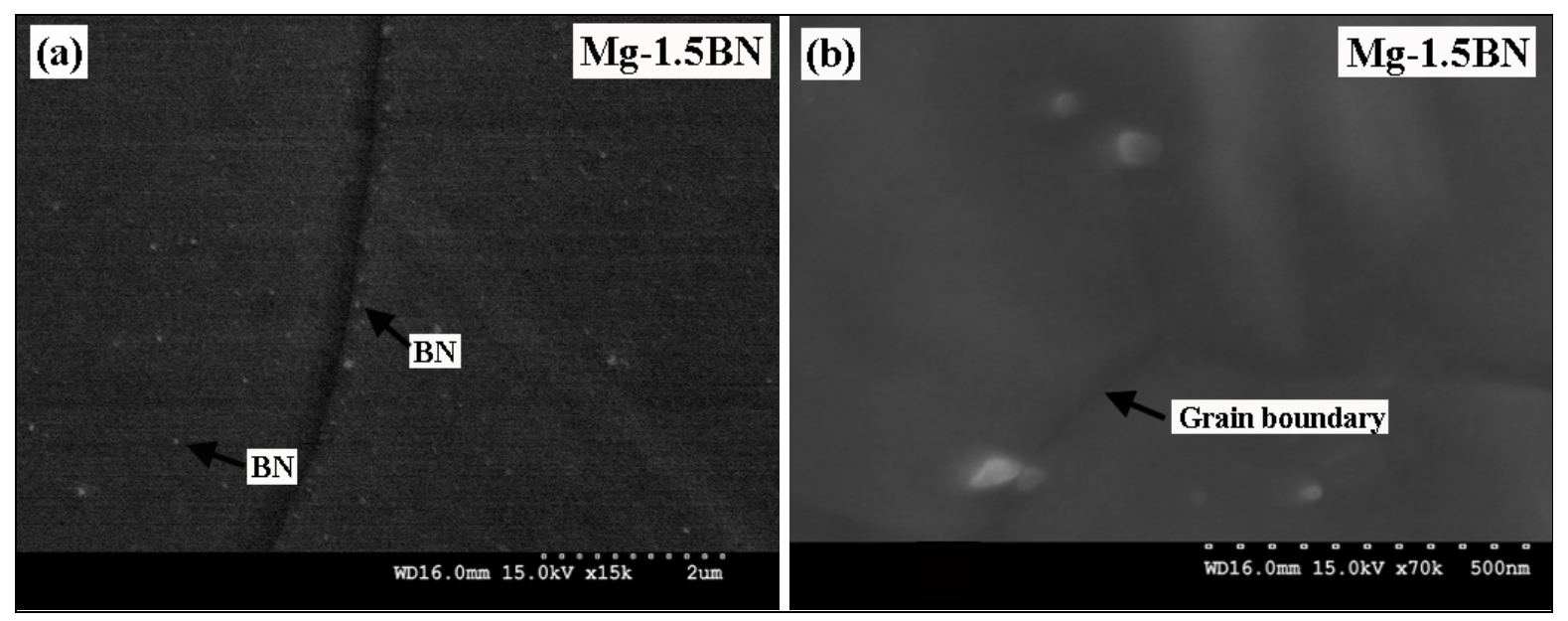

Microstructural characterization further revealed good interfacial integrity between Mg-matrix and nano-BN reinforcement (Figure 2b) assessed in terms of interfacial debonding at the particulate-matrix interface. During processing, the oxidation of BN particulates cannot be completely ruled out, as the billet temperature reaches the near melting temperature of $\mathrm{Mg}$ and the formation enthalpy of $\mathrm{B}_{2} \mathrm{O}_{3}$ $(-1262 \mathrm{~kJ} / \mathrm{mol})$ is more negative than $\mathrm{MgO}(-600 \mathrm{~kJ} / \mathrm{mol})$ [19]. The $\mathrm{B}_{2} \mathrm{O}_{3}$ phase (if present) will exist in the liquid state because of its low melting point $\left(\sim 500{ }^{\circ} \mathrm{C}\right)$. Further, the reaction of $\mathrm{B}_{2} \mathrm{O}_{3}$ with molten $\mathrm{Mg}$ could result in the formation of intermetallic phases, such as $\mathrm{MgO}$ and $\mathrm{MgB}_{2} \mathrm{O}_{5}[19,20]$. The good interfacial integrity (absence of debonding and voids) at the particulate-matrix interface observed in the present case (Figure $2 b$ ) could attribute to the possible presence of oxide layer at the particle-matrix interface $[21,22]$. Such a good particle-matrix interface with coherent interfacial reaction products is expected to improve the strength of composite by interfacial strengthening [22]. However, the degree of interface strengthening will be greatly affected by the inherent properties of interfacial reaction products and the distribution of second phases in the matrix.

\subsection{Coefficient of Thermal Expansion}

The thermal expansion coefficients of monolithic $\mathrm{Mg}$ and $\mathrm{Mg} / \mathrm{BN}$ composites measured in the temperature range $50{ }^{\circ} \mathrm{C}$ to $400{ }^{\circ} \mathrm{C}$ are presented in Table 3 . It indicates an improvement in dimensional stability (reduction in the coefficient of thermal expansion (CTE) values) through the addition of nanoscale BN particulates. The experimental CTE values were then compared to that of the theoretical values calculated based on the rule of mixtures Equation (1) and the turner model Equation (2).

$$
\begin{aligned}
& \text { Rule of Mixtures: } \alpha_{c}=\alpha_{m} V_{m}+\alpha_{r} V_{r} \\
& \text { Turner model: } \alpha_{c}=\frac{\left(\alpha_{m} V_{m} K_{m}+\alpha_{r} V_{r} K_{r}\right)}{\left(V_{m} K_{m}+V_{r} K_{r}\right)}
\end{aligned}
$$

where $\alpha, \mathrm{V}$ and $\mathrm{K}$ represent the coefficient of thermal expansion, volume fraction and bulk modulus of the phase; while the subscripts, $m$ and $r$, refer to matrix and reinforcement, respectively [23]. Using the 
values of $\alpha_{\mathrm{m}} \sim 28.4 \times 10^{-6} / \mathrm{C}, \mathrm{K}_{\mathrm{m}} \sim 35.6 \mathrm{GPa}, \alpha_{\mathrm{r}} \sim 1.2 \times 10^{-6} / \mathrm{C}$ and $\mathrm{Kr} \sim 145 \mathrm{GPa}$, the coefficient of thermal expansion of the composites were computed [24]. The comparison, as shown in Table 3, indicates that the experimental values were lower than both the theoretical values, as in these models, the effects of particle size on the thermal expansion coefficient has not been considered. Xu et al. [25] has studied the effects of varying the particle sizes and has reported that the degree of constraints posed by the particles on the matrix varies with respect to the particles sizes and, hence, affects the coefficient of thermal expansion.

Table 3. Results of coefficient of thermal expansion (CTE) measurements. ROM, rule of mixtures.

\begin{tabular}{ccccc}
\hline & & \multicolumn{2}{c}{ Thermal expansion coefficient $(\mathbf{C T E})\left(\times \mathbf{1 0}^{-\mathbf{6}} / \mathbf{K}\right)$} \\
\cline { 3 - 4 } S. No. & Material & \multicolumn{2}{c}{ Theoretical } & \multirow{2}{*}{ Experimental } \\
\cline { 3 - 4 } & & ROM & Turner model & 28.52 \\
& Pure Mg & 28.40 & 28.40 & 27.19 \\
2 & Mg-0.5BN & 28.32 & 28.08 & 26.82 \\
3 & Mg-1.5BN & 28.17 & 27.47 & 24.63 \\
4 & Mg-2.5BN & 28.01 & 26.87 & \\
\hline
\end{tabular}

\subsection{X-ray Diffraction Studies}

The results of X-ray diffraction studies conducted along the cross section and longitudinal sections of developed $\mathrm{Mg} / \mathrm{BN}$ nanocomposites are shown in Figure 3. The high intensity peaks corresponding to $\mathrm{Mg}$ were prominently seen, and the peaks corresponding to the $\mathrm{BN}$ reinforcement particulates and other related peaks were not prominent. This could be due to their relatively low volume fraction $(<2.5$ vol.\%) in the $\mathrm{Mg}$ matrix, which would remain undetected by the technique of XRD [12]. However, the presence of these reinforcements can be confirmed from the microstructural investigation, in Figure 2.

The results of X-ray analysis were used to interpret the effect of nano-BN addition on the crystallographic orientation (specifically, the basal plane orientation) of Mg-matrix, as it is known, that the reinforcing phases could contribute to the change in basal orientation (texture) of the Mg-crystal [26]. The peaks observed at $2 \theta=32^{\circ}, 34^{\circ}$ and $36^{\circ}$ diffraction pattern of developed

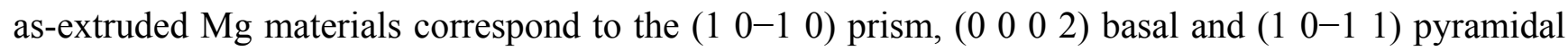
planes of HCP Mg-crystal [27]. Along the cross-section, the prismatic plane intensity $\left(2 \theta=32^{\circ}\right)$ is maximum in all the cases, which indicates that any of the prismatic planes is aligned in a direction, which is perpendicular to the extrusion direction. Also, the basal plane intensity $\left(2 \theta=34^{\circ}\right)$ is found increasing with respect to the nano-BN addition, and in the case of $\mathrm{Mg}-2.5 \mathrm{BN}$, the basal plane intensity is equally dominant, similar to the prismatic plane. Similarly, along the longitudinal section, the intensity of basal plane is found to be maximum in the case of pure $\mathrm{Mg}$ and the composites with a lower BN volume fraction (i.e., < $2.5 \mathrm{wt} . \%$ ). This shows that most of the basal planes are aligned parallel to the extrusion direction, indicating a strong basal texture, which is commonly observed in the wrought $\mathrm{Mg}$ materials [27]. However, in case of $\mathrm{Mg}-2.5 \mathrm{BN}$, a change in the intensity of the peaks is clearly observed along the longitudinal section in which the intensity of the pyramidal plane $\left(2 \theta=36^{\circ}\right)$ 
is found to be maximum. This indicates that the basal planes remain tilted and are not parallel to the extrusion direction, suggesting randomization of the extrusion texture [27]. Similar texture randomization is reported by Garces et al. [28] and Wang et al. [29], wherein it was shown that the presence of micron-sized ceramic particulates contribute to texture weakening, as seen by the reduction in the intensity of basal texture in the X-ray pole figure. Similarly, the presence of nano-BN particle reinforcements appeared to have the ability to reduce the basal intensity in the current study.

Figure 3. Results of X-ray characterization studies conducted along the (a) cross section; and (b) longitudinal sections on the extruded rods of developed $\mathrm{Mg}$ based materials.

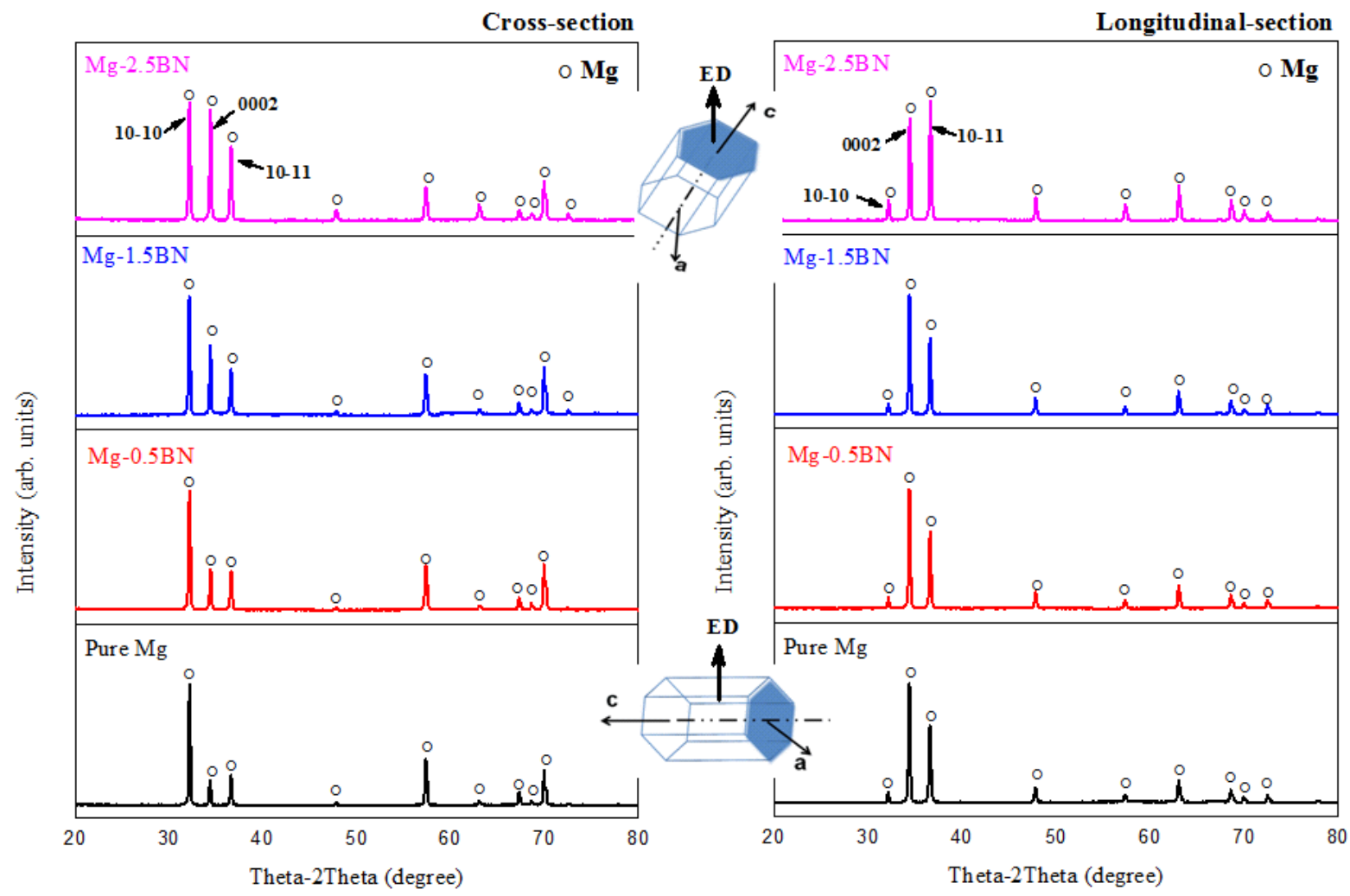

(a)

(b)

\subsection{Mechanical Behavior}

The microhardness $\left(\mathrm{H}_{\mathrm{v}}\right)$ values of pure $\mathrm{Mg}$ and its composites reinforced with nano-BN particulates are listed in Table 4. It indicates that the nanoscale addition of $\mathrm{BN}$ to $\mathrm{Mg}$ resulted in the improvement in microhardness values. The increase in microhardness values could be primarily attributed to the relatively uniform distribution of nanoscale $\mathrm{BN}$ particulates and its higher constraint to the localized matrix deformation during indentation [2,3]. The microhardness values of $\mathrm{Mg} / \mathrm{BN}$ composites were found to be proportional to the reinforcement volume fraction and observed to be consistent with dispersion strengthened metallic materials reported in the literature [8].

The results of a room temperature tensile test conducted on the developed $\mathrm{Mg} / \mathrm{BN}$ composites are listed in Table 5. From the results, significant improvement in ultimate tensile strength was observed when compared to $\mathrm{Mg}$. However, considering the standard deviation, the $0.2 \%$ yield strength values were found to be similar between the monolithic $\mathrm{Mg}$ and its composites. In similar studies wherein the 
nanoscale reinforcement addition resulted in superior strength properties, the yield strength improvement is attributed to the Hall-Petch grain boundary strengthening effect offered by the increased grain boundary area by grain refinement and the presence of uniformly distributed dispersed phases, which impedes the dislocations movement $[3,8,12]$. While the uniform distribution of nanoscale BN reinforcements in the current study is expected to significantly improve the yield strength by effectively obstructing the dislocation movement, the minimal grain refinement would contribute less towards the grain boundary strengthening.

Table 4. Results of microhardness measurements.

\begin{tabular}{ccc}
\hline S. NO. & Material & Microhardness $\mathbf{H}_{\mathbf{v}}$ \\
\hline 1 & Pure Mg & $48 \pm 1$ \\
2 & Mg- $0.5 \mathrm{BN}$ & $51 \pm 3$ \\
3 & Mg-1.5BN & $55 \pm 3$ \\
4 & Mg-2.5BN & $57 \pm 2$ \\
\hline
\end{tabular}

Table 5. Results of room temperature tensile test.

\begin{tabular}{ccccc}
\hline S. No. & Material & 0.2 YS [MPa] & UTS [MPa] & Fracture Strain [\%] \\
\hline 1 & Pure Mg & $136 \pm 8$ & $170 \pm 7$ & $6.1 \pm 1.2$ \\
2 & Mg-0.5BN & $127 \pm 6$ & $192 \pm 8$ & $7.8 \pm 0.9$ \\
3 & Mg-1.5BN & $142 \pm 4$ & $200 \pm 5$ & $8.6 \pm 0.5$ \\
4 & Mg-2.5BN & $145 \pm 3$ & $217 \pm 5$ & $7.2 \pm 0.8$ \\
\hline
\end{tabular}

Further, the literature study reveals the effect of crystallographic texture modification on the yield strength properties of magnesium materials [4,7,28-32]. In the present study, the basal texture of composite samples was observed to be weak when compared to pure $\mathrm{Mg}$, i.e., the minimal basal planes intensity seen on XRD results (Figure 3) along the longitudinal sections of composite samples compared to pure $\mathrm{Mg}$. In composites/nanocomposites, the addition of reinforcements usually improves the yield strength [8]. In the present case, an increase in yield strength is expected because of BN addition. However, due to the observed change in Mg-crystal orientation, the increase in yield strength is not significant. This is due to the fact that the texture weakening usually would result in the activation of basal slip at relatively lower stress levels. Such competing factors result in the yield strength values of composites being similar to pure $\mathrm{Mg}$ (Table 5) [31,32]. However, the presence of nano-BN particles in Mg-matrix was useful in improving the ultimate tensile strength in composites by the dispersion strengthening effect attributing to the modulus mismatch and the thermal residual stress due to the mismatch in thermal expansion coefficients between the matrix and reinforcing phases $[2,3,8]$.

In general, extruded magnesium materials exhibit poor tensile ductility, which is attributed to the strong basal fiber texture of $\mathrm{Mg}$, wherein the basal planes are aligned preferentially parallel to the extrusion direction [27]. In similar studies, the enhancement in tensile ductility was achieved by the combination of (i) grain refinement; (ii) possible activation of non-basal slip systems by the uniform distribution of nanoscale reinforcements; and (iii) texture modification $[2,3,8,11,12]$. In the current study, the uniform distribution of nano-BN particles in magnesium matrix as evident from the microstructural characterization (Figure $2 b$ ) would result in the activation of non-basal and cross-slip 
and, thereby, increase the failure strain in the developed Mg-composites [8,12,33-35]. Another important factor, which can be considered for the ductility improvement, is the change in crystallographic texture observed from the XRD pattern (Figure 3). It shows that most of the basal planes in the composites were titled at an angle, which is neither parallel nor perpendicular to the extrusion direction. The basal slip can be easily activated in such a case due to the slight misalignment of the basal plane as the critical resolved shear stress is very low for the basal slip to activate $[12,34,35]$.

The fractographic evidence of the developed $\mathrm{Mg}$ materials under tensile loading showing the fracture mechanism is shown in Figure 4. It reveals similar fracture features, indicating the cleavage mode of fracture in pure $\mathrm{Mg}$ and its composites under tensile loading. From the similar fracture features observed in the fractographs, it could be understood that the fracture behavior of developed $\mathrm{Mg} / \mathrm{BN}$ composites was largely controlled by the matrix deformation characteristics. However, a high magnification image (Figure 4e) shows relatively increased slip activity in Mg-2.5BN. Usually, owing to the HCP crystal structure, the plastic deformation in magnesium is limited, due to the lack of sufficient slip activity, and the cleavage steps seen in the tensile fractographs (Figure 4) are the indications of the inability of uniform deformation in $\mathrm{Mg}[5,8]$.

Figure 4. Tensile fracture surfaces of (a) pure $\mathrm{Mg}$; (b) $\mathrm{Mg}-0.5 \mathrm{BN}$; (c) $\mathrm{Mg}-1.5 \mathrm{BN}$; and (d) $\mathrm{Mg}-2.5 \mathrm{BN}$ composites; (e) a high magnification image showing increased slip activity in $\mathrm{Mg}-2.5 \mathrm{BN}$.
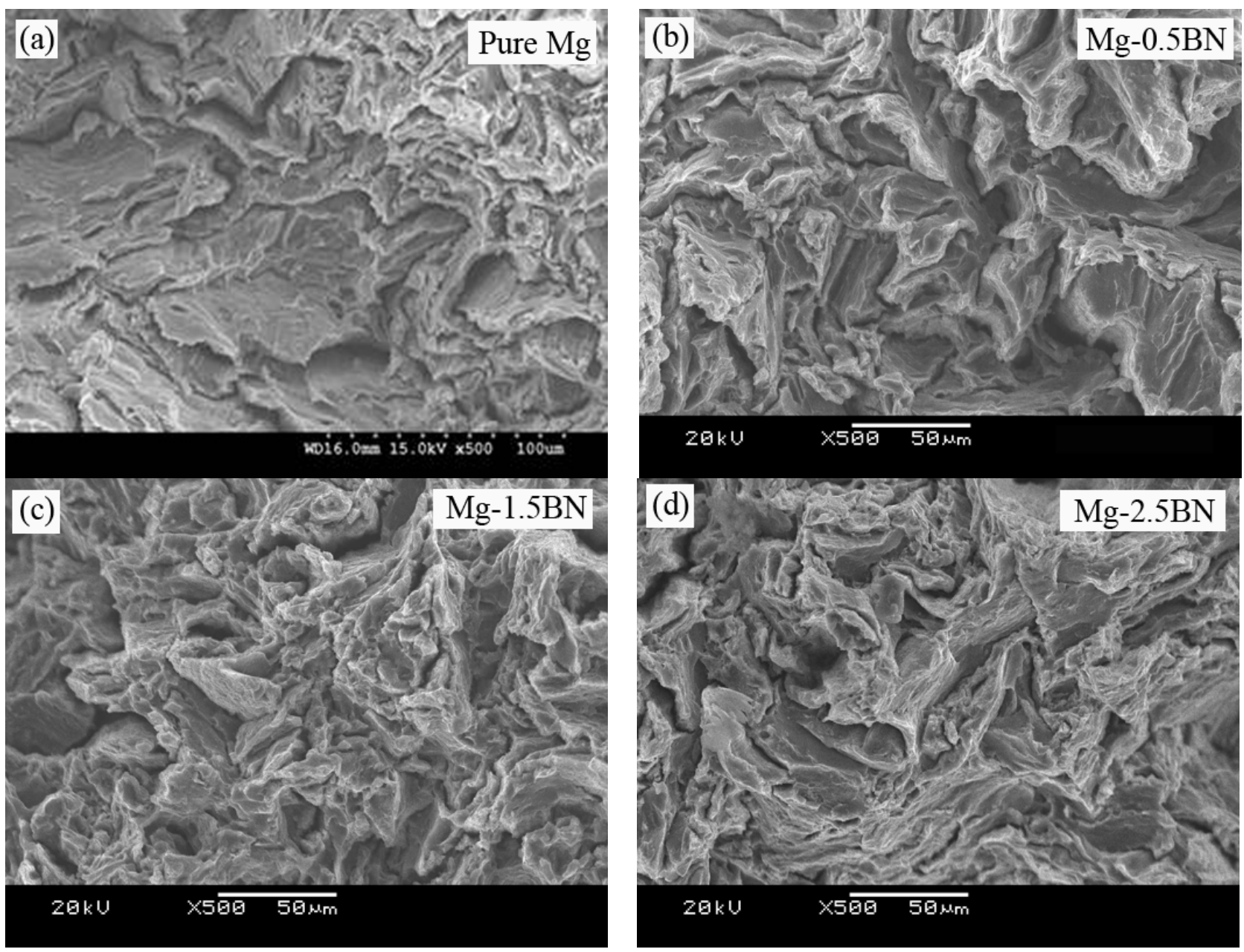
Figure 4. Cont.

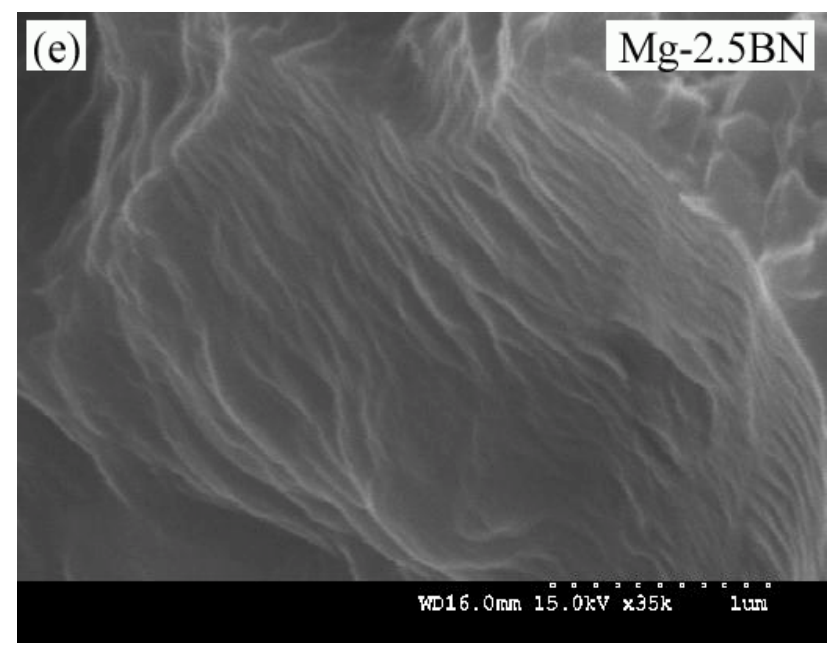

The room temperature compressive properties of developed Mg-nanocomposites are listed in Table 6. Unlike under tensile loading, where the improvement in ultimate tensile strengths due to nano-BN addition occurred with similar yield strengths (Table 5), the improvement in compressive strength properties were accompanied by a significant improvement in compressive yield strength (Table 6). In the case of extruded Mg materials with strong basal texture (with basal planes parallel to the extrusion direction), higher yield strength under tensile loading and lower yield strength under compressive is commonly observed [28,29]. This is attributed to the difference in deformation mode and the initial crystallographic orientation.

Table 6. Results of room temperature compression test.

\begin{tabular}{ccccc}
\hline S. No. & Material & 0.2 CYS (Mpa) & UCS (Mpa) & Fracture Strain (\%) \\
\hline 1 & Pure Mg & $70 \pm 2$ & $250 \pm 7$ & $24.5 \pm 2.7$ \\
2 & Mg-0.5BN & $88 \pm 6$ & $290 \pm 9$ & $20.9 \pm 1.8$ \\
3 & Mg-1.5BN & $108 \pm 2$ & $312 \pm 8$ & $19.9 \pm 1.2$ \\
4 & Mg-2.5BN & $115 \pm 4$ & $319 \pm 4$ & $19.7 \pm 1.4$ \\
\hline
\end{tabular}

A comparison of yield strength under tension and compression is shown in Figure 5; in which the tension/compression yield asymmetric ratio is also provided. It indicates a minimal difference in yield asymmetry ( $\left.\frac{\text { Tensile Yield Strength }}{\text { Compressive Yield Strength }}\right)$ for $\mathrm{Mg} / 2.5 \mathrm{BN}$ composite in which the c-axis is misaligned in comparison to pure $\mathrm{Mg}$, where the c-axis is parallel to the loading/extrusion axis (basal planes oriented perpendicular to the extrusion direction). The higher tensile yield strength under tensile loading often results from the difficulty in basal slip activation and the inability of twinning $[7,28,29]$ in the case of strong fiber texture, as seen in pure Mg. Further; the formation and propagation of tensile twins were favored at relatively lower strength levels, which results in higher fracture strain, while the presence of dispersed phases in the case of composites obstructs the twin nucleation and propagation. Hence; the restricted twinning process in the case of composites delays the yield process, which contributes to the higher strength properties and the poor failure strain. The fracture surface analysis of monolithic $\mathrm{Mg}$ and its composites under compressive loading conditions reveals the presence of shear bands as shown 
in Figure 6. The presence of such shear bands indicates the twinning mode of plastic deformation, which is common in Mg alloys and composites [4,36].

Figure 5. Comparison of tensile and compressive yield strengths in pure $\mathrm{Mg}$ and its $\mathrm{Mg} / \mathrm{BN}$ composites.

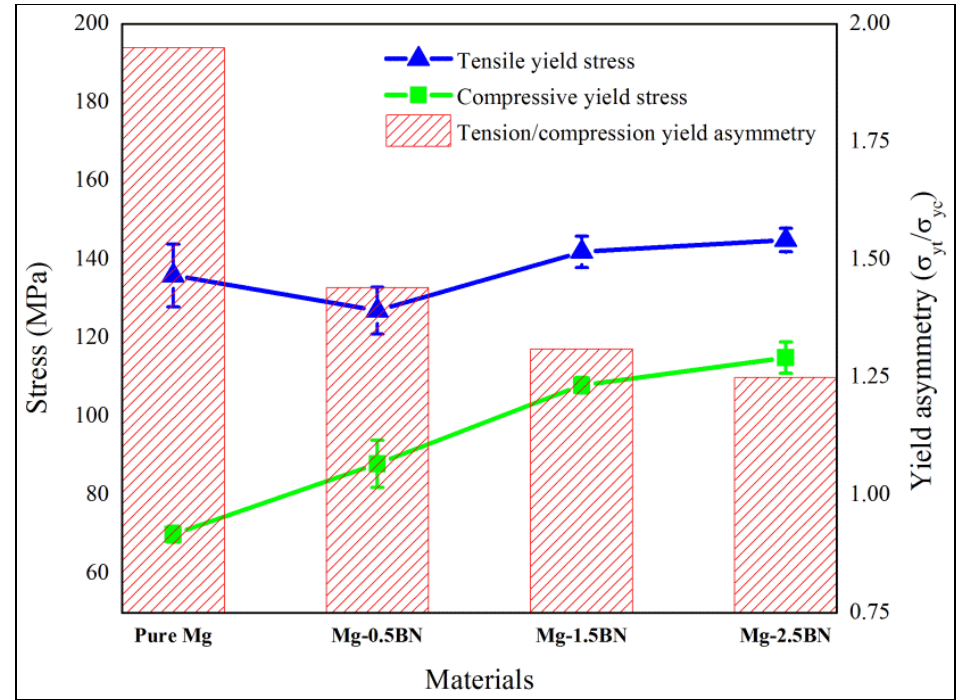

Figure 6. Representative compressive fracture surfaces showing shear bands in (a) pure $\mathrm{Mg}$; (b) $\mathrm{Mg}-0.5 \mathrm{BN}$; (c) $\mathrm{Mg}-1.5 \mathrm{BN}$; and (d) $\mathrm{Mg}-2.5 \mathrm{BN}$ composites.
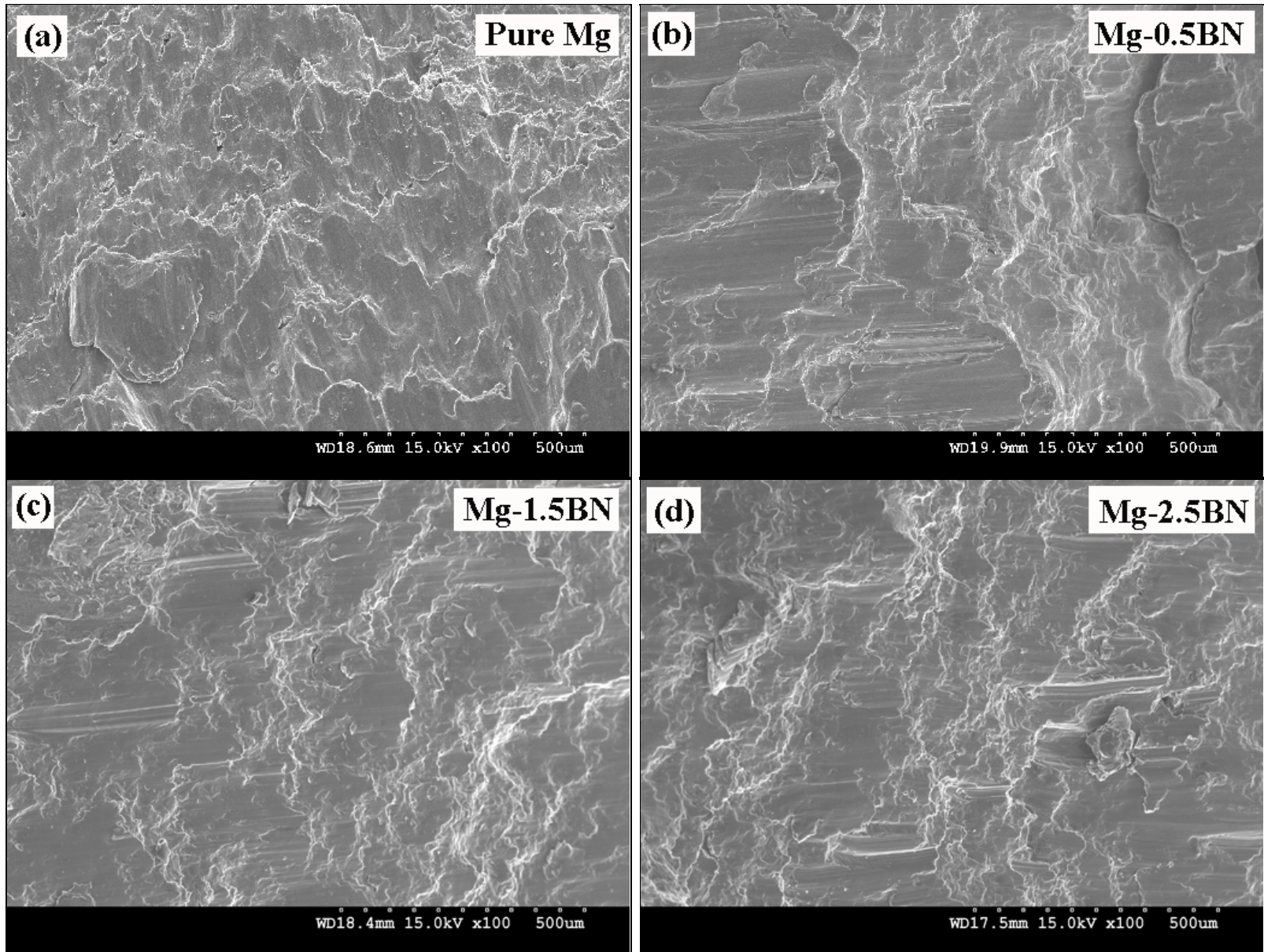


\section{Experimental Procedure}

\subsection{Materials}

In this work, magnesium powder of $98.5 \%$ purity with a size range of $60-300 \mu \mathrm{m}$ (Merck, Germany) was used as the matrix material, and nano-sized boron nitride (BN) particulates of particle size $\sim 50 \mathrm{~nm}$ (Nabond, Hong Kong, China) were used as the reinforcement. The amount of nanosized $\mathrm{BN}$ was varied from 0.5 to $2.5 \mathrm{wt} . \%$.

\subsection{Synthesis}

Pure $\mathrm{Mg}$ and its nano-BN particulate reinforced composites required for the current study were synthesized using the powder metallurgy technique $[15,16]$. The synthesis process involved blending pure magnesium powder with different volume fractions of nanosized BN powder in a RETSCH PM-400 mechanical alloying machine (RETSCH, Hanna, Germany) at $200 \mathrm{rpm}$ for $1 \mathrm{~h}$. No balls or process control agent was used during the blending step, and the blending process was carried out without any protective atmosphere. The blended Mg-powder mixture was then uniaxially cold compacted at the pressure of 50 tons into billets of the size of $35 \mathrm{~mm}$ diameter and $40 \mathrm{~mm}$ length. The compacted billets were sintered using a hybrid microwave assisted two-directional sintering technique $[15,16]$. The billets were heated for $14 \mathrm{~min}$ to a temperature near the melting point of $\mathrm{Mg}$ in a $900 \mathrm{~W}, 2.45 \mathrm{GHz}$ Sharp microwave oven using colloidal graphite as an oxidation barrier layer. After sintering, the sintered billets were coated with colloidal graphite and soaked at $400{ }^{\circ} \mathrm{C}$ for $1 \mathrm{~h}$ and hot extruded at $350{ }^{\circ} \mathrm{C}$ at an extrusion ratio of $20.25: 1$, to obtain rods of $8 \mathrm{~mm}$ in diameter. Samples from the extruded rods were used for further characterization.

\subsection{Materials Characterization}

\subsubsection{Density Measurements}

The density of extruded $\mathrm{Mg}$ and $\mathrm{Mg}$ nanocomposites in the polished condition was measured using Archimedes' principle [16]. Three samples were randomly selected from extruded rods and were weighed in air and then immersed in distilled water. An A\&D ER-182A electronic balance with an accuracy of $0.0001 \mathrm{~g}$ was used for recording the weights. Theoretical densities of the samples were calculated using the rule-of-mixture principle.

\subsubsection{Coefficient of Thermal Expansion}

An INSEIS TMA PT 1000LT thermo-mechanical analysis instrument was used to determine the thermal expansion coefficients (CTE) of the as-extruded monolithic $\mathrm{Mg}$ and composite samples. A heating rate of $5{ }^{\circ} \mathrm{C} / \mathrm{min}$ was maintained. An argon gas flow rate was maintained at $100 \mathrm{~cm} / \mathrm{min}$. Displacement of the test samples (each $5 \mathrm{~mm}$ long) as a function of temperature $\left(50-400{ }^{\circ} \mathrm{C}\right.$ ) was measured using an alumina probe and was subsequently used to determine the CTE. The experimentally obtained values were then compared to that of the theoretical values calculated using the rule of mixtures and the turner model. 


\subsubsection{Microstructure}

Microstructural characterization studies were conducted to determine the average matrix grain size, its morphology and distribution, the presence and distribution of reinforcement and the interface between the matrix and reinforcing phase. Microstructural analyses were carried out on short sections of the extruded rod. A small section ( 8 to $10 \mathrm{~mm}$ in length) was cut from each extruded rod of different composition. Cutting was done at low speed using a diamond blade wheel cutter to produce samples with fairly flat ends. The ends of the sample were then ground using 600 and 1200 grit size sand paper to remove the large surface scratches and also to produce a flat surface. Once all visible surface scratches and cracks were removed, the sample was polished using a polishing disc with 5 micron alumina slurry, followed by 1 micron alumina slurry and lastly by 0.3 micron alumina slurry. The surface of the polished samples was etched with acetic picral $(10 \mathrm{~mL}$ acetic acid, $4.2 \mathrm{~g}$ picric acid, $70 \mathrm{~mL}$ ethanol, $10 \mathrm{~mL} \mathrm{H}_{2} \mathrm{O}$ ) to make the grain boundaries visible. Acetic picral was applied onto the surface of the sample by dabbing the surface for a duration of 5 to 10 seconds, before the surface was rinsed under running water. These samples were then observed in optical microscopy and scanning electron microscopy to see the grain size, morphology and for secondary phases. The microstructures were studied using optical microscope (Olympus, Tokyo, Japan) and field emission scanning electron microscope (FESEM-S4300, Hitachi Ltd., Tokyo, Japan) coupled with energy dispersion analysis (EDS). In quantitative metallography, the characterization of the primary grain structure involves the measurement of the grain size and grain aspect ratio. Using selected optical/SEM microstructures from various compositions, the grain characteristics were determined using the Scion image analysis software. From the micrographs, using the software, the area of each grain and the values of major and minor axes of each grain can be obtained. From the values of the grain area, the average grain diameter is calculated; while from the ratio of major and minor axes, the average aspect ratio of the grains are obtained. A total of 120-150 grains were selected to calculate the grain characteristics.

\subsubsection{X-ray Diffraction Studies}

X-ray diffraction analysis was carried out on the polished extruded $\mathrm{Mg}$ and $\mathrm{Mg} / \mathrm{BN}$ composite samples using an automated SHIMADZU LAB-X XRD-6000 diffractometer (SHIMADZU, Kyoto, Japan). The samples were exposed to $\mathrm{CuK} \alpha$ radiation $(\lambda=1.54056)$ at a scanning speed of $2 \% \mathrm{~min}$. The Bragg angle and the values of the interplanar spacing (d) obtained were subsequently matched with the standard values for $\mathrm{Mg}, \mathrm{BN}$ and other related phases. Further, the basal plane orientation of the developed $\mathrm{Mg}$ composites was analyzed based on the XRD peaks obtained from experiments carried out in directions both parallel and perpendicular to the extrusion axis.

\subsubsection{Mechanical Behavior}

Mechanical behavior of monolithic and composite samples was assessed in terms of microhardness, tensile and compressive properties. Microhardness measurements were performed on the polished samples using a MATSUZAWA MXT 50 automatic digital microhardness tester (MATSUZAWA, Kyoto, Japan). The microhardness test was performed using a Vickers indenter under a test load of 25 gf and a dwell time of $15 \mathrm{~s}$ in accordance with the ASTM standard E384-99 [17]. 
The tensile and compressive properties of the as-extruded pure magnesium and its composite counterparts were determined in accordance with the procedures outlined in ASTM standard E8M-01 and ASTM E9-89a using an MTS 810 automated servo hydraulic mechanical testing machine [12]. The crosshead speed was set at $0.254 \mathrm{~mm} / \mathrm{min}$ and $0.04 \mathrm{~mm} / \mathrm{min}$ for the tension and compression test, respectively. For each composition, a minimum of 6 tests were conducted to obtain repeatable values. The fractured samples under tensile and compressive loading of $\mathrm{Mg}$-materials were analyzed using a Hitachi S-4300 FESEM to identify the fracture mechanisms.

\section{Conclusions}

$\mathrm{Mg}$ composites reinforced with nanoscale $\mathrm{BN}$ particulates were successfully synthesized using microwave-assisted sintering technique, and the effects of nano-BN particulates addition on the microstructural and mechanical properties of $\mathrm{Mg}$ were studied. Based on the structure-property correlation, the following conclusions are drawn.

1. The addition of nanoscale $\mathrm{BN}$ reinforcements marginally reduced the average grain size and CTE and increased the hardness when compared to monolithic $\mathrm{Mg}$.

2. XRD studies conducted on developed $\mathrm{Mg} / \mathrm{BN}$ composites showed basal texture weakening with an increase in nano-BN addition.

3. Under tensile loads, the developed $\mathrm{Mg} / \mathrm{BN}$ nanocomposites exhibit similar yield strength and enhanced ultimate tensile strength and ductility attributed to the strengthening effect and non-basal slip activation.

4. Under compressive loads, the addition of nano-BN particulates significantly enhanced the strength and reduced the ductility owing to the difficulty in twinning and slip dominated flow.

5. The reduction of tension-compression yield asymmetry ratio was attributed to the weakening of strong basal texture in pure $\mathrm{Mg}$.

\section{Acknowledgements}

The authors gratefully acknowledge the financial support from Qatar National Research Foundation through research grant \# NPRP08-424-2-171 (R-265-000-346-597). One of the authors, S. Sankaranarayanan, sincerely thanks the NUS research scholarship for supporting this research for his graduate program.

\section{References}

1. Kainer, K.U.; Buch, F. Magnesium Alloys and Technology; Wiley-VCH: Weinheim, Germany, 2003; pp. 1-22.

2. Lloyd, D.J. Particle reinforced aluminium and magnesium matrix composites. Int. Mater. Rev. 1994, 39, 1-23.

3. Dieter, G.E. Mechanical Metallurgy; McGraw-Hill: New York, NY, USA, 1986.

4. Wang, Y.N.; Huang, J.C. Review: Texture analysis in hexagonal materials. Mater. Chem. Phys. 2003, 81, 11-26. 
5. Yoo, M.H. Slip, twinning, and fracture in hexagonal close-packed metals. Metall. Trans. A 1981, 12, 409-418.

6. Yoshinaga, H.; Obara, T.; Morozumi, S. Twinning deformation in magnesium compressed along the C-Axis. Mater. Sci. Eng. 1973, 12, 255-264.

7. Gehrmann, R.; Frommert, M.M.; Gottstein, G. Texture effects on plastic deformation of magnesium. Mater. Sci. Eng. A 2005, 395, 338-349.

8. Gupta, M.; Ling, M. Magnesium Technology; Wiley-VCH: Weinheim, Germany, 2011.

9. Hassan, S.F.; Gupta, M. Development of high performance magnesium nano-composites using nano- $\mathrm{Al}_{2} \mathrm{O}_{3}$ as reinforcement. Mater. Sci. Eng. A 2005, 392, 163-168.

10. Dieringa, H. Properties of magnesium alloys reinforced with nanoparticles and carbon nanotubes. J. Mater. Sci. 2011, 46, 289-306.

11. Goh, C.S.; Wei, J.; Lee, L.C.; Gupta, M. Properties and deformation behaviour of $\mathrm{Mg}-\mathrm{Y}_{2} \mathrm{O}_{3}$ nanocomposites. Acta Mater. 2007, 55, 5115-5121.

12. Tun, K.S.; Jayaramanavar, P.; Nguyen, Q.B.; Chan, J.; Kwok, R.; Gupta, M. Investigation into tensile and compressive responses of $\mathrm{Mg}-\mathrm{ZnO}$ composites. Mater. Sci. Technol. 2011, 28, $582-588$.

13. Lee, K.B.; Sim, H.S.; Heo, S.W.; Yoo, H.R.; Cho, S.Y.; Kwon, H. Tensile properties and microstructures of $\mathrm{Al}$ composite reinforced with BN particles. Composities Part A Appl. Sci. Manuf. 2002, 33, 709-715.

14. Xia, Z.P.; Li, Z.Q.; Lu, C.J.; Zhang, B.; Zhou, Y. Structural evolution of Al/BN mixture during mechanical alloying. J. Alloys Compd. 2005, 399, 139-143.

15. Gupta, M.; Wong, E. Microwaves and Metals; John Wiley: Hoboken, NJ, USA, 2007.

16. Wong, W.L.E.; Gupta, M. Enhancing overall mechanical performance of metallic materials using two-directional microwave assisted rapid sintering. Scr. Mater. 2005, 52, 479-483.

17. Humphreys, F.J.; Hatherly, M. Recrystallisation and Related Annealing Phenomena; Pergamon: Oxford, UK, 1995.

18. Mabuchi, M.; Kubota, K.; Higashi, K. Effect of hot extrusion on the mechanical properties of a Mg-Si-Al Alloy. Mater. Lett. 1994, 19, 247-250.

19. Lavrenko, V.A.; Gogotsi, Y.G. Influence of oxidation on the composition and structure of the surface layer of hot-pressed boron carbide. Oxidat. Metals 1988, 29, 193-202.

20. Lynch, C.T. CRC Handbook of Materials Science; CRC Press Inc.: Boca Raton, FL, USA, 1984.

21. Gu, M.Y.; Wu, Z.G; Jin, Y.P.; Koçak, M. The interfacial reaction and microstructure in a ZK60-based hybrid composite. J. Mater. Sci. 2000, 35, 2499-2505.

22. Nikhilesh, C.; Chawla, K.K. Metal Matrix Composites; Springer: New York, NY, USA, 2006.

23. Turner, P.S. Thermal-expansion stresses in reinforced plastics. J. Res. Natl. Bur. Stand. 1946, 37, 239-260.

24. Smithells, C.J. Metals Reference Book, 5th ed.; Butterworth's \& Co. Ltd.: London, UK, 1976.

25. Xu, Z.R.; Chawla, K.K.; Mitra, R.; Fine, M.E. Effect of particle size on the thermal expansion of Tic/A1 XDTM Composites. Scr. Metall. Mater. 1994, 31, 1525-1530.

26. Stanford, N.; Atwell, D.; Beer, A.; Davies, C.; Barnett, M.R. Effect of microalloying with rare-earth elements on the texture of extruded magnesium-based alloys. Scripta Mater. 2008, 59, $772-775$. 
27. Jayalakshmi, S.; Sankaranarayanan, S.; Koh, S.P.X.; Gupta, M. Effect of Ag and Cu trace additions on the microstructural evolution and mechanical properties of $\mathrm{Mg}-5 \mathrm{Sn}$ alloy. J. Alloys Compd. 2013, 565, 56-65.

28. Garces, G.; Rodriguez, M.; Perez, P.; Adeva, P. Effect of volume fraction and particle size on the microstructure and plastic deformation of $\mathrm{Mg}_{-} \mathrm{Y}_{2} \mathrm{O}_{3}$ composites. Mater. Sci. Eng. A 2006, 419, $357-364$.

29. Garces, G.; Perez, P.; Adeva, P. Effect of the extrusion texture on the mechanical behaviour of Mg-SiCp composites. Scripta Mater. 2005, 52, 615-619.

30. Wang, X.L.; Yu, Y.; Wang, E.D. The effects of grain size on ductility of AZ31 magnesium alloy. Mater. Sci. Forum 2005, 488-489, 535-538.

31. Mukai, T.; Yamanoi, M.; Watanabe, H.; Higashi, K. Ductility enhancement in AZ31 magnesium alloy by controlling its grain structure. Scripta Mater. 2001, 45, 89-94.

32. Kleiner, S.; Uggowitzer, P.J. Mechanical anisotropy of extruded Mg-6\% Al-1\% Zn alloy. Mater. Sci. Eng. A 2004, 379, 258-263.

33. McDanels, D.C. Analysis of stress-strain, fracture, and ductility behavior of aluminum matrix composites containing discontinuous silicon carbide reinforcement. Metall. Trans. 1985, A16, $1105-1115$.

34. Kettunen, P.O.; Kuokkala, V.T. Plastic Deformation and Strain Hardening; Trans Tech: Enfield, NH, USA, 2002.

35. Koike, J.; Kobayashi, T.; Mukai, T.; Watanabe, H.; Suzuki, M.; Maruyama, K.; Higashi, K. The activity of non-basal slip systems and dynamic recovery at room temperature in fine-grained AZ31B magnesium alloys. Acta Mater. 2003, 51, 2055-2065.

36. Kima, H.L.; Lee, J.H.; Lee, C.S.; Bang, W.; Ahn, S.H.; Chang, Y.W. Shear band formation during hot compression of AZ31 Mg alloy sheets. Mater. Sci. Eng. A 2012, 558, 431-438.

(C) 2013 by the authors; licensee MDPI, Basel, Switzerland. This article is an open access article distributed under the terms and conditions of the Creative Commons Attribution license (http://creativecommons.org/licenses/by/3.0/). 